\title{
Prevalence of Epstein-Barr Virus in Patients with Ulcerative Colitis Using Polymerase Chain Reaction (PCR)
}

\author{
Maryam Derakhshan ${ }^{1}$, Pegah Hedayat ${ }^{1}$, Rozhan Mohammadi ${ }^{1,}$, , Amirsajad Barahimi ${ }^{2}$ \\ ${ }^{1}$ Department of Pathology, Al-Zahra Hospital, Isfahan University of Medical Sciences, Isfahan, Iran \\ ${ }^{2}$ Department of General Physician, Al-Zahra Hospital, Isfahan University of Medical Sciences, Isfahan, Iran
}

Email address:

m_derakhshan58@yahoo.com (M. Derakhshan), Hedayat_pegah2000@yahoo.com (P. Hedayat), asimaghami@yahoo.com (R. Mohammadi),Barahimi_amir@yahoo.com (A. Barahimi)

${ }^{*}$ Corresponding author

\section{To cite this article:}

Maryam Derakhshan, Pegah Hedayat, Rozhan Mohammadi, Amirsajad Barahimi. Prevalence of Epstein-Barr Virus in Patients with Ulcerative Colitis Using Polymerase Chain Reaction (PCR). Pathology and Laboratory Medicine. Vol. 2, No. 1, 2018, pp. 20-24. doi: $10.11648 /$ j.plm.20180201.14

Received: June 22, 2018; Accepted: August 3, 2018; Published: September 10, 2018

\begin{abstract}
Ulcerative colitis (UC) is still controversial and recent researches referred to the role of infectious factors such as EBV in this disease, but the relationship between EBV and UC has not yet been proven. Therefore, the present study evaluates the prevalence of EBV in patients with UC and comparison with control group by Polymerase Chain Reaction (PCR). In this study, 30 samples of intestinal biopsy in patients with UC in the active phase of disease and 30 biopsy samples from non-UC subjects were evaluated by PCR method were evaluated by PCR method and the presence or absence of EBV virus in the sample was recorded. Finally, the collected data were analyzed by SPSS (Ver.22) software. As the result EBV was found in 10 biopsies of 30 from UC patients and 3 of 30 biopsies from non-UC-patients $(33.3 \%$ vs. $10 \%$, P-value $=0.028)$. Also, the prevalence of this virus in the both groups was not significantly different in terms of sex and age (P-value $>0.05)$. Therefore, it may conclude that evidence of infection of the virus in mucosal inflammatory cells of patients with UC has an important role in chronic UC. Given the small sample size, it is suggested that future studies to be carried out with similar subject in a larger population of these patients.
\end{abstract}

Keywords: Epstein-Barr Virus, Ulcerative Colitis, Polymerase Chain Reaction

\section{Introduction}

Inflammatory bowel disease (IBD) is currently considered as the common cause of gastrointestinal tract infections, especially in developed countries [1]. This disease represents a group of inflammatory and chronic bowel disorders [2]. Ulcerative colitis (UC) is a type of IBD, causing inflammation and ulceration in the large intestine [3] and affects about 2 in every 1,000 population, which is a high prevalence [4].

The definitive etiology of this complication is unclear, but several factors, including bacterial factors, nutritional factors, psychological factors, immunologic factors, and genetics have been recognized to be involved $[5,6]$. Recently, the involvement and role of EBV in the development of IBD has been reported [7-9] so that EBV was detected in colonoscopy biopsy samples as well as pathologic examination of the intestine.

The virus is a double-stranded DNA herpes virus, which can infect humans worldwide, and it persists in more than $90 \%$ of humans worldwide [10]. In fact, it causes persistent infection in the infected host $[11,12]$. EBV infection frequently causes self-limiting infectious mononucleosis [12].

EBV is associated with a number of human malignancies including, Burkitt lymphoma, nasopharyngeal carcinoma, UC, and so on [13, 14]. In some previous studies, a relationship was found between $\mathrm{UC}$ disease and $\mathrm{EBV}$ infection 15, 8]. EBV infection in patients with UC, especially those who are treated with steroids and who have immunodeficiency, can cause severe systemic illness and often leads into colectomy. In this regard, polymerase chain reaction (PCR) is known as the most sensitive laboratory method, or used in associated with in-situ hybridization or 
immunohistochemistry to detect viral infections such as EBV $[16,17]$. Therefore, UC tissues were examined for the presence of EBV-related DNA using PCR method.

On the other hand, given the importance of UC and unknown nature of its etiology, diagnosis of infectious factors in these patients may have important effects on treatment and prevention; therefore, the present study compared the prevalence of EBV in case group (UC patients) and control group using PCR method.

\section{Materials and Methods}

This case-control study was carried out on all patients undergoing intestinal biopsy presented at the pathology department of al-Zahra hospital during 2012-2016. According to the sample size formula, to compare the prevalence of the disease in the two independent groups, the confidence level of $95 \%$ and power of $80 \%$ and considering the EBV prevalence ratio of $0.26,30$ cases were considered in each group.

In the case group, 30 patients with UC under intestinal biopsy were randomly selected.

Infection with UC was based on histologic criteria and these patients were in the active phase of the disease in accordance with the Mayo Score, and if the quality of the sample was inappropriate to determine the presence of EBV virus protein by the PCR method, it was excluded from the study. In the control group, 30 non-UC subjects who were undergone biopsy due to other reasons, were randomly selected using convenience sampling. In this group, they were excluded from the study if the symptoms of irritable bowel syndrome and malignancy were observed (no case was excluded from the study). It is of interest that the Mayo Score is a combined endoscopic and clinical scale used to assess the severity of UC. This score was initially proposed by Schroeder et al. in 1987 in a clinical trial of 5-ASA drugs in $\mathrm{UC}$ and has been used in various subsequent clinical trials and clinical practices. The Mayo Score is a composite of subscores from four categories, including stool frequency, rectal bleeding, and findings of flexible proctosigmoidoscopy or colonoscopy, and physician's global assessment [18].

The scores were ranged 0-3 for each factor, and the Mayo score or disease activity index (DAI) score for ulcerative colitis sets between 0 and 12 . If $\mathrm{DAI} \leq 2$, the patient is considered to be in the remission phase, and DAI scores between 10-3 are considered mild to moderate, and in DAI> 10 , disease is considered to be severe. After obtaining written informed consent from each patient, demographic and clinical information as well as their endoscopic reports were recorded. Then, sample of UC patient's intestine biopsy underwent PCT test for determining the presence of protein and DNA of the EBV virus. This reaction was performed by the function of a DNA polymerase, which can replicate a DNA strand in optimal conditions.

To set out PCR, the reaction mixture was warmed up to denature two strands of targeted DNA and then it was cooled down to anneal primers to a specific sequence in the targeted DNA. Then, DNA polymerase begins to expand any primer at the end of its extension. The products were isolated by heating from the targeted DNA and each product was achieved from one thermocycler. Finally, the presence or absence of the EBV virus in the evaluated sample was recorded.

At the end collected data were analyzed using SPSS (Ver. 22) through Fisher's exact tests, Chi-square, and MannWhitney statistical tests, and for all analyzes significance level was considered to be less than 0.05 .

\section{Results}

In this study from 30 cases of ulcerative colitis, 18 ones $(60 \%)$ were males and $12(40 \%)$ were females with the mean age of $35.6 \pm 11.63$ years, and from 30 subjects in the control group, $16(53.3 \%)$ were males and $14(46.7 \%)$ were female with the mean age of $31.63 \pm 8.62$ years, which were statistically matched in terms of age and gender ( $\mathrm{P}$ value $>$ 0.05).

In addition, the results of PCR indicated that EBV was seen in $33.3 \%$ of the case group and in $10 \%$ of the control group $(\mathrm{P}$ value $=0.028)($ Table 1$)$.

Table 1. Determination and comparison of the presence of Epstein-Barr virus in the two groups.

\begin{tabular}{|c|c|c|c|c|}
\hline Characteristics & & Control $(n=30)$ & Case $(n=30)$ & P value \\
\hline \multirow{2}{*}{ Sex } & Male & $16(53.3 \%)$ & $18(60 \%)$ & \multirow{2}{*}{0.795} \\
\hline & Female & $14(46.7 \%)$ & $12(40 \%)$ & \\
\hline Age; year & & $31.13 \pm 8.62$ & $35.00 \pm 11.63$ & 0.149 \\
\hline Family history & & $7(23.3 \%)$ & $2(23.3 \%)$ & 0.996 \\
\hline \multirow{2}{*}{ EBV } & Negative & $27(90 \%)$ & $20(66.7 \%)$ & \multirow{2}{*}{0.028} \\
\hline & Positive & $3(10 \%)$ & $10(33.3 \%)$ & \\
\hline
\end{tabular}

The highest EBV prevalence in the case group was in men with 7 out of 10 cases $(70 \%)$ with the mean age of $39.38 \pm$ 8.31 years and also in the men of control group with 2 out of 3 cases $(66.7 \%)$ with the mean age of $34.00 \pm 7.55$ years $(\mathrm{P}$ value $>0.05$ ) (Table 2).

In addition, the evaluation of gender and the mean age distribution of EBV-positive individuals in both case and control groups indicated that despite the higher prevalence of the virus in the males of case group than females and in the older patients but these differences were not known significant ( $\mathrm{P}$ value $>0.05)$. 
Table 2. Determination and comparison of demographic characteristics of patients with ulcerative colitis in terms of Epstein-Barr virus in each of the two groups.

\begin{tabular}{|c|c|c|c|c|c|}
\hline \multirow{2}{*}{ Group } & \multirow{2}{*}{ Characteristics } & & \multicolumn{2}{|l|}{ EBV } & \multirow{2}{*}{ P value } \\
\hline & & & Negative $(n=20)$ & Positive (n=10) & \\
\hline \multirow{5}{*}{ Case } & \multirow{2}{*}{ Sex } & Male & $9(45 \%)$ & $7(70 \%)$ & \multirow{2}{*}{0.260} \\
\hline & & Female & $11(55 \%)$ & $3(30 \%)$ & \\
\hline & Age; year & & $32.60 \pm 12.47$ & $39.80 \pm 8.31$ & 0.041 \\
\hline & \multirow{2}{*}{ Family history } & No & $16(80 \%)$ & $7(70 \%)$ & \multirow{2}{*}{0.657} \\
\hline & & Yes & $4(20 \%)$ & $3(30 \%)$ & \\
\hline Group & Characteristics & & $\begin{array}{l}\text { Negative } \\
(\mathrm{n}=27)\end{array}$ & $\begin{array}{l}\text { Positive } \\
(\mathrm{n}=3)\end{array}$ & $P$ value \\
\hline \multirow{5}{*}{ Control } & \multirow{2}{*}{ Sex } & Male & $16(59.3 \%)$ & $2(66.7 \%)$ & \multirow{2}{*}{0.804} \\
\hline & & Female & $11(40.7 \%)$ & $1(33.3 \%)$ & \\
\hline & Age; year & & $30.81 \pm 8.81$ & $34.00 \pm 7.55$ & 0.553 \\
\hline & \multirow{2}{*}{ Family history } & No & $26(92.3 \%)$ & $2(66.7 \%)$ & \multirow{2}{*}{0.701} \\
\hline & & Yes & $1(3.7 \%)$ & $1(33.3 \%)$ & \\
\hline
\end{tabular}

In addition, the Mayo criterion factors including Stool frequency, Rectal bleeding, Mucosal appearance at endoscopy, Physician rating of disease activity, and family history had no relationship with EBV virus (P value> 0.05) (Table3).
The mean Mayo Score / Disease Activity Index (DAI) for ulcerative colitis in patients with positive EBV was $14.2 \pm$ 4.49 and in patients with negative EBV was $13.32 \pm 1.91$, which did not show a significant difference $(P$ value $=0.911)$ (Figure 1).

Table 3. Mayo Disease Activity of Ulcerative Colitis Patients regarding Epstein Barr Virus.

\begin{tabular}{|c|c|c|c|c|c|}
\hline \multirow{2}{*}{\multicolumn{2}{|c|}{ Mayo Disease Activity }} & \multirow{3}{*}{$\begin{array}{l}\text { Case }(n=30) \\
8(26.7 \%)\end{array}$} & \multicolumn{2}{|l|}{ EBV } & \multirow{2}{*}{ P value } \\
\hline & & & Negative $(n=20)$ & Positive $(n=10)$ & \\
\hline \multirow{4}{*}{ Stool frequency } & Normal & & $6(30.0 \%)$ & $2(20.0 \%)$ & \multirow{4}{*}{0.599} \\
\hline & $1-2$ stools/day more than normal & $8(26.7 \%)$ & $6(30.0 \%)$ & $2(20.0 \%)$ & \\
\hline & 3-4 stools/day more than normal & $10(33.3 \%)$ & $5(25.0 \%)$ & $5(50.0 \%)$ & \\
\hline & $>4$ stools/day more than normal & $4(13.3 \%)$ & $3(15.0 \%)$ & $1(10.0 \%)$ & \\
\hline \multirow{4}{*}{ Rectal bleeding $\dagger$} & None & $10(33.3 \%)$ & $5(25.0 \%)$ & $5(50.0 \%)$ & \multirow{4}{*}{0.567} \\
\hline & Visible blood with stool less than half the time & $12(40.0 \%)$ & $9(45.0 \%)$ & $3(30.0 \%)$ & \\
\hline & Visible blood with stool half of the time or more & $5(16.7 \%)$ & $4(20.0 \%)$ & $1(10.0 \%)$ & \\
\hline & Passing blood alone & $3(10.0 \%)$ & $2(10.0 \%)$ & $1(10.0 \%)$ & \\
\hline \multirow{4}{*}{$\begin{array}{l}\text { Mucosal } \\
\text { appearance at } \\
\text { endoscopy }\end{array}$} & Normal or inactive disease & $2(6.7 \%)$ & $2(10.0 \%)$ & $0(0.0 \%)$ & \multirow{4}{*}{0.363} \\
\hline & Mild disease $^{*}$ & $6(20.0 \%)$ & $3(15.0 \%)$ & $3(30.0 \%)$ & \\
\hline & Moderate disease ${ }^{* *}$ & $15(50.0 \%)$ & $9(45.0 \%)$ & $6(60.0 \%)$ & \\
\hline & Severe disease ${ }^{* * *}$ & $7(23.3 \%)$ & $6(30.0 \%)$ & $1(10.0 \%)$ & \\
\hline \multirow{4}{*}{$\begin{array}{l}\text { Physician rating } \\
\text { of disease activity }\end{array}$} & Normal & $4(13.3 \%)$ & $3(15.0 \%)$ & $1(10.0 \%)$ & \multirow{4}{*}{0.081} \\
\hline & Mild & $12(40.0 \%)$ & $9(45.0 \%)$ & $3(30 \%)$ & \\
\hline & Moderate & $11(36.7 \%)$ & $7(35.0 \%)$ & $4(40.0 \%)$ & \\
\hline & Severe & $3(10.0 \%)$ & $1(5.0 \%)$ & $2(20.0 \%)$ & \\
\hline
\end{tabular}

$\dagger$ : Assigning a score of 3 requires patients to have $\geq 50 \%$ of bowel movement accompanied by visible blood and $1+$ bowel movement with blood alone.

* Mild disease: erythema, decreased vascular pattern, mild friability

** Moderate disease: marked erythema, absent vascular pattern, friability, erosions

*** Severe disease: spontaneous bleeding, ulceration 


\section{Significance level of the Mann-Whitney test $=0.911$}

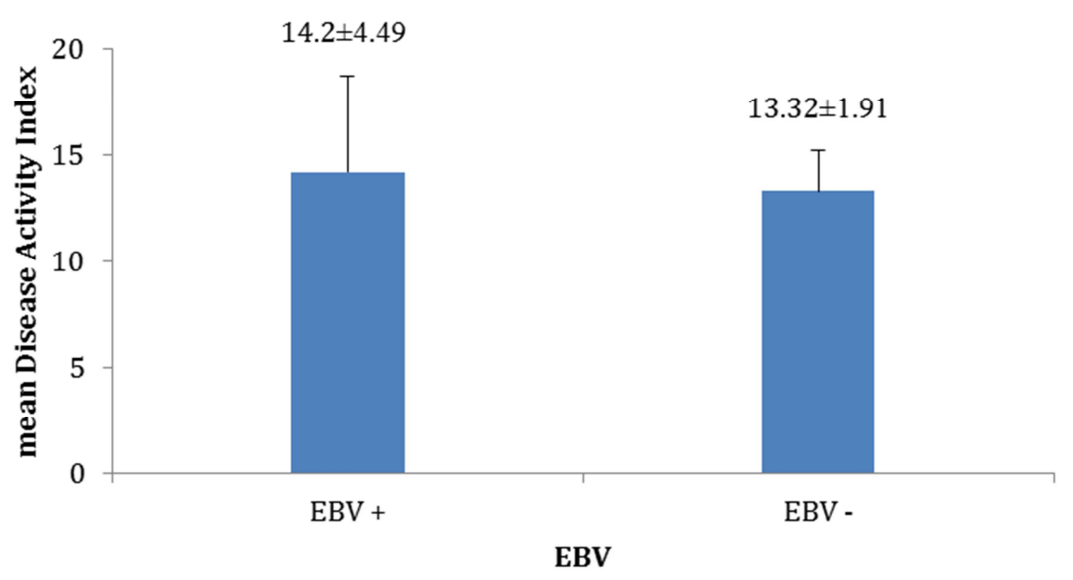

Figure 1. Determine and compare the mean of DAI score in terms of the Epstein-Barr virus.

\section{Discussion}

The present study was performed on the two groups of 30 UC patients and non-UC individuals, which were matched for age and sex and according to the results, in 10 cases $(33.3 \%)$ of the biopsy samples of patients with UC and in 3 cases $(10 \%)$ of the intestinal biopsy samples of the control group DNA related to EBV was found $(\mathrm{P}$ value $=0.028)$. It should be noted that DAI score in EBV positive patients with UC was negligibly higher than the EBV negative patients with UC (P value $>0.05)$.

In addition, although at the older ages or in men (especially in UC patients), the EBV viral load is a little more than women, but these two factors (age and gender) in either group can't be related to EBV infection or non-infection.

Also, there was no significant difference between the patients with $\mathrm{EBV}+$ in the two groups in terms of age, sex and family history of disease ( $P$ value $>0.05$ ).

EBV is an opportunistic pathogenic microorganism. In recent years, the relationship between UC and the presence of EBV has been investigated by researchers. Despite a large number of reports, the pathogenesis role of EBV in these patients is still unknown. Some physicians have reported both UC and EBV colitis [19].

In line with this study, many studies have also shown the presence of EBV in a biopsy sample of patients with UC [14, $20,21]$. For example, Bertalot et al found that 6 out of the 23 biopsy samples and 4 out of the 6 colectomy samples in patients with ulcerative colitis contained protein and EBV virus and DNA, and thus they have reported the probable role of EBV in infection of the UC patients. [8] Matsumoto et al (2014) reported in their case report that EBV-related DNA was diagnosed to be positive in serum samples of patients with severe hemorrhagic colitis. In contrast, EBV-related DNA was not diagnosed in the blood when colitis recovered. Therefore, they claimed that the severe hemorrhagic colitis in the patient was related to EBV [22], while they have referred to need for more case studies in this regard. In contrary to the present study, Mehrabani-Khasragh et al. (2016) in their study found EBV prevalence in $60 \%$ of biopsy samples of UC patients and in $36.7 \%$ of the healthy population, but they revealed that there was not a significant relationship between EBV-DNA and UC infection[23].

In the current study, this difference was statistically significant and notable, suggesting that there was a significant relationship between EBV and UC.

In addition, they were evaluated the role of demographic characteristics such as age, sex and family history of EBV in both control and control groups and there was no correlation between these factors and the EBV infection in either group that were in line with the current study.

The results of many previous studies using the PCR method indicated the presence of EBV in the gastrointestinal tract of patients with IBD [7, 9, 24]. It has also been argued that EBV and other viruses of the herpesvirus family are involved in the pathogenesis of IBD [7-9].

In fact EBV-positive lymphocytes accumulate in $\mathrm{UC}$, suggesting the colon as a potential site for EBV replication [16].

Rizzo et al. (2017) also evaluated the frequency of colonic EBV in patients with inflammatory bowel disease (IBD), microscopic colitis (MC) and ulcerative colitis (UC) in their study and they reported that EBV DNA was detected in 27 MC patients of 30 , in 20 of 30 UC cases, and in none of IBS group. The frequency of EBV DNA in MC was significantly higher than UC $(\mathrm{p}=0.03)$. EBERs + cells were observed in 18 cases of $30 \mathrm{MC}$ patients, in only 3 out of $30 \mathrm{UC}$ patients $(p<0.001)$, and in none of IBS group [25].

The findings are presented here wanted to evaluate the prevalence of EBV in patients with $\mathrm{UC}$ and ultimately the presence of the virus in the biopsy sample of these patients in comparison with the control group was found significant. But used small sample size is a fundamental limitation in the study that causes to not be able to generalize the results.

Given the carcinogenic role of the virus in infecting different colon cells (23), it is needed that carcinogenesis mechanism to be clarified in further studies. On the other hand, as existence or absence of association between EBV and UC has not been proven, further studies are needed 
between the two large populations of patients with and without UC.

\section{Conclusions}

According to the results of the present study, EBV virus was found in one third of the biopsy samples of UC patients as well as one tenth of non-UC patients. It suggests a significantly higher presence of EBV in UC patients than non-UC patients. Moreover, although the Mayo Score for Ulcerative Colitis (UC) was higher in patients with EBV positive compared to those with EBV negative, the difference was not significant. It may imply on the EBV-induced infection in mucosal inflammatory cells of UC patients and its role in developing chronic UC. However, it requires further studies with larger sample size to achieve more decisive results can be generalized to the population. Also, the presence of EBV in other diseases (such as IBD, MC and UC) can be compared with each other as topics for further research.

\section{References}

[1] Torres J, Mehandru S, Colombel JF, Peyrin-Biroulet L. Crohn's disease. Lancet 2017; 389:1741-1755.

[2] Aghazadeh R, Zali MR, Bahari A, Amin K, Ghahghaie F, Firouzi F. Inflammatory bowel disease in Iran: a review of 457 cases. J GastroenterolHepatol 2005; 20(11): 1691-5.

[3] Ungaro R, Mehandru S, Allen PB, Peyrin-Biroulet L, Colombel JF. Ulcerative colitis. Lancet 2017; 389:1756-1770.

[4] Mokhtari M, Hashemi JM, Davarpanah JA. Prevalence of Anti-EBV Antibodies in Adult Patients with Nasopharyngeal Carcinoma During 2003-2007 In Isfahan, Iran. Iranian Journal of Cancer Prevention, 2009; 1(4): 173-177.

[5] Haahr S, H?llsberg P. Multiple sclerosis is linked to EpsteinBarr virus infection. Rev Med Virol 2006; 16(5): 297-310.

[6] Green C, Elliott L, Beaudoin C, Bernstein CN. A. populationbased ecologic study of inflammatory bowel disease: searching for etiologic clues. Am J Epidemiol 2006; 164(7): 615-23.

[7] Linton MS, Kroeker K, Fedorak D, Dieleman L, Fedorak RN. Prevalence of Epstein-Barr Virus in a population of patients with inflammatory bowel disease: a prospective cohort study. Alimentary pharmacology \& therapeutics. 2013 Nov 1; 38(10):1248-54.

[8] Mokhtari M, Bahraini M, Masoudifar A. EPSTEIN-BARR VIRUS NUCLEAR ANTIGEN EXPRESSION (EBNA) IN PAPILLARY THYROID CARCINOMA. Journal of Fundamental and Applied Sciences. 2016 Feb 15; 8(2S):2360-5.

[9] Magro F, Santos-Antunes J, Albuquerque A, Vilas-Boas F, Macedo GN, Nazareth N, Lopes S, Sobrinho-Simões J, Teixeira S, Dias CC, Cabral J. Epstein-Barr Virus in Inflammatory Bowel Disease-Correlation with Different Therapeutic Regimens. Inflammatory bowel diseases. 2013 Jul 1; 19(8):1710-6.

[10] Cohen JI: Epstein-Barr virus infection. N Engl J Med 2000; 343:481-492.
[11] Liebowitz D. Pathogenesis of Epstein-Barr virus. In: McCance DJ, Editor. Human tumor viruses. Washington, DC: American Society for Microbiology; 1998. p. 175-9.

[12] Luzuriaga K, Sullivan JL: Infectious mononucleosis. N Engl J Med 2010; 362:1993-2000.

[13] Yanai H, Shimizu N, Nagasaki S, Mitani N, Okita K. EpsteinBarr virus infection of the colon with inflammatory bowel disease. Am J Gastroenterol 1999; 94(6): 1582-6.

[14] Gehlert T, Devergne O, Niedobitek G. Epstein-Barr virus (EBV) infection and expression of the interleukin-12 family member EBV-induced gene 3 (EBI3) in chronic inflammatory bowel disease. J Med Virol 2004; 73(3): 432-8.

[15] Satsangi J, Silverberg MS, Vermeire S, Colombel JF. The Montreal classification of inflammatory bowel disease: controversies, consensus, and implications. Gut 2006; 55:749.

[16] Spieker T, Herbst H. Distribution and phenotype of EpsteinBarr virus-infected cells in inflammatory bowel disease. Am J Pathol 2000; 157(1): 51-7.

[17] Wakefield AJ, Fox JD, Sawyerr MA, Taylor JE, Sweenie CH, Smith M, et al. Detection of herpesvirus DNA in the large intestine of patients with ulcerative colitis and Crohn's disease using the nested polymerase chain reaction. Journal of Medical Virology 1992; 38(3): 183-90.

[18] Schroeder KW, Tremaine WJ, Ilstrup DM. Coated oral 5aminosalicylic acid therapy for mildly to moderately active ulcerative colitis. A randomized study, N Engl J Med, 1987; 317: $1625-29$.

[19] Dimitroulia E, Pitiriga VC, Piperaki ET, Spanakis NE, Tsakris A. Inflammatory bowel disease exacerbation associated with Epstein-Barr virus infection. Dis Colon Rectum 2013; 56(3): 322-7.

[20] Takeda Y, Takada K, Togashi H, Takeda H, Sakano M, Osada Y, et al. Demonstration of Epstein-Barr virus localized in the colonic and ileal mucosa of a patient with ulcerative colitis. GastrointestEndosc 2000; 51(2): 205-9.

[21] Ameli M, Khalily F. Analysis ulcerative colitis for presence Epstein-Barr virus DNA sequences by polymerase chain reaction technique. Journal of Analytical Research in Clinical Medicine. 2016 Jan 1; 4(1):9-13.

[22] Matsumoto H, Kimura Y, Murao T, Osawa M, Akiyama T, Mannoji K, Koresawa R, Tokunaga H, Wada H, Sugihara T, Haruma K. Severe colitis associated with both epstein-barr virus and cytomegalovirus reactivation in a patient with severe aplastic anemia. Case reports in gastroenterology. 2014; $8(2): 240-4$.

[23] Mehrabani-Khasraghi S, Ameli M, Khalily F. Analysis ulcerative colitis for presence Epstein-Barr virus DNA sequences by polymerase chain reaction technique. J Anal Res Clin Med, 2016; 4(1): 9-13.

[24] Ryan JL, Shen YJ, Morgan DR, Thorne LB, Kenney SC, Dominguez RL, Gulley ML: Epstein-Barr virus infection is common in inflamed gastrointestinal mucosa. Dig Dis Sci 2012; 57:1887-1898.

[25] Rizzo AG, Orlando A, Gallo E, Bisanti A, Sferrazza S, Montalbano LM, Macaluso FS, Cottone M. Is Epstein-Barr virus infection associated with the pathogenesis of microscopic colitis?. Journal of Clinical Virology. 2017; 97:1-3. 